\title{
VALORES E PRÁTICAS CORPORAIS DE MULHERES SOBRE SEUS CORPOS: CONFIANÇA, DOR E VERGONHA NO EXAME PAPANICOLAU
}

\author{
CAMPOS, Edemilson Antunes de ${ }^{1}$ \\ OLIVEIRA, Régia Cristina ${ }^{2}$
}

RESUMO: O exame Papanicolau tem por objetivo o diagnóstico precoce do câncer de colo de útero, uma doença que apresenta, no país, altas taxas de mortalidade e prevalência. No entanto, sentimentos como vergonha, constrangimento e dor durante o exame tem sido apontados como fatores que dificultam a adesão ao mesmo, em especial, entre mulheres de camadas populares. O presente artigo tem por objetivo analisar as experiências da realização do referido exame entre mulheres pertencentes a essas camadas. $\mathrm{O}$ artigo parte de pesquisa etnográfica desenvolvida com nove mulheres, moradoras de um bairro periférico da zona leste de São Paulo, que realizam o exame Papanicolau. Foram realizadas entrevistas semi estruturadas e observações de visitas de agente de saúde a essas mulheres. Como resultados podem ser destacados a existência de um confronto entre o que é prescrito na preparação para o exame e o que as mulheres consideram necessário e significativo em termos de práticas corporais. Ao mesmo tempo, evidenciou-se que a existência de confiança na eficácia médica acaba por ressignificar a dor durante o exame. O reconhecimento, escuta e acolhimento pelo profissional de saúde dos sentimentos que acompanham a realização do exame pode favorecer uma melhor adesão ao mesmo.

Palavras-chave: Corpo feminino. Dor. Vergonha. Biomedicina. Exame Papanicolau.

\section{VALUES AND BODILY PRACTICES OF WOMEN ON THEIR BODIES: CONFIDENCE, PAIN AND SHAME IN PAP SMEAR}

\begin{abstract}
SUMMARY: The PAP examination aims at early diagnosis of cervical cancer, a disease that presents high mortality and prevalence rates in the country. However, feelings such as shame, embarrassment and pain during the examination have been pointed out as factors that hinder adherence to the same, especially among women of popular layers. The purpose of this article is to examine the experiences of the realization of the said examination among women belonging to these layers. The article part of ethnographic research developed with nine women, resident of a peripheral neighborhood of the East zone of Sao Paulo, which carry out the Pap smear exam. Semi-structured interviews were carried out and observations of health agent visits to these women. As result can be highlighted the existence of a confrontation between what is prescribed in the preparation for the exam and what are women consider necessary and meaningful in terms of bodily practices. At the same time, it was evidenced that the existence of confidence in medical efficacy turns out to give new meaning to pain during the examination. The recognition, listening and welcoming by the health professional of the feelings that accompany the realization of the examination can favor a better adherence to it.
\end{abstract}

Keywords: Female body. Pain. Shame. Biomedicine. Pap smear exam

\section{INTRODUÇÃO}

O presente artigo tem por objetivo analisar as experiências da realização do exame Papanicolau entre mulheres pertencentes a camadas populares, enfocando desde a preparação para o exame e, com ela,

\footnotetext{
${ }^{1}$ Doutor em Ciências Sociais (UFSC), Docente da Universidade de São Paulo, na Escola de Artes, Ciências e Humanidades - EACH/ USP

${ }^{2}$ Doutora em Sociologia (USP), Docente da Universidade de São Paulo, na Escola de Artes, Ciências e Humanidades - EACH/USP
} 
as práticas corporais e seus significados, até o encontro com o profissional de saúde, por ocasião da realização do exame, e os sentimentos e emoções que acompanham cada um desses momentos.

Partimos de perspectiva teórica que toma o corpo e as emoções como construção social e cultural e não uma realidade em si (LE BRETON, 2006; 2009; 2011). Pensados como não restritos à dimensão biológica, o corpo e as emoções constituem-se em sistemas simbólicos. Nesses termos, o corpo pode ser pensado, como define Douglas (1991, p. 138), como "um símbolo da sociedade", logo, ser tomado como uma linguagem, que é adquirida culturalmente (SARTI, 2001), assim com as emoções.

Fenômeno culturalmente construído, as emoções demandam, para sua compreensão, da consideração do contexto e das circunstâncias em que aparecem, das pessoas envolvidas e dos valores em cena.

O presente texto, que visa abordar corpo e emoções nessa perspectiva antropológica, parte de uma pesquisa que buscou apreender, a partir de trabalho etnográfico (SARTI, 2003; CAMPOS, 2013), as práticas e os significados elaborados em torno do exame Papanicolau, enfocando as lógicas que regem as práticas de cuidados de mulheres moradoras de Keralux, um bairro popular da cidade de São Paulo.

\section{O CAMINHO DA PESQUISA E O PERFIL DAS MULHERES ENTREVISTADAS}

A partir de um trabalho etnográfico, fundamentado nos princípios de uma "descrição densa" (GEERTZ, 1989), foram realizadas, primeiramente, observações no referido bairro, buscando-se a familiarização com o local, o bairro Jd Keralux, localizado na periferia da zona leste, na cidade de São Paulo. Em seguida, foram feitas observações de visitas de agente de saúde às casas das mulheres que potencialmente poderiam ser entrevistadas, e, finalmente, foram realizadas entrevistas semiestruturadas com nove mulheres ${ }^{3}$ que fazem o exame Papanicolau, pelo menos uma vez por ano. As entrevistas tiveram duração média de uma hora cada. As entrevistas foram transcritas e analisadas por meio da técnica da análise de conteúdo ( MINAYO, 2009).

A pesquisa etnográfica realizada neste trabalho priorizou o contato direto do pesquisador com as mulheres em idade reprodutiva, moradoras do referido bairro.

Essas mulheres são de origem nordestina e estão em São Paulo há pelo menos 10 anos. Com relação à situação familiar, quatro são casadas, três são solteiras e uma, viúva. Todas elas têm filho, a maioria delas, apenas um. Das nove mulheres entrevistadas, cinco delas tem apenas um filho, as duas mulheres com maior número de filhos, uma delas com quatro e outra, com cinco, são casadas. Com exceção de uma das mulheres, viúva, que é dona de casa, sete trabalham em serviços gerais e de limpeza, outra entrevistada trabalha como auxiliar de cozinha e uma mencionou trabalhar operando máquina. Todas trabalham em locais próximos ao bairro onde moram.

A Unidade Básica de Saúde (UBS) é o único acesso ao serviço de saúde dessa população, majoritariamente atendida pelo sistema público. É nesse local que realizam o Papanicolau e, para tanto, desenvolvem práticas consideradas por elas higiênicas, de preparação do próprio corpo para esse exame.

\section{AS IMPUREZAS DO CORPO FEMININO: A PREPARAÇÃO PARA O EXAME}

A enfermeira do postinho fala que não precisa. Ela sempre fala, mas eu tenho vergonha. Aí, eu me depilo. Eu fico com vergonha se eu não depilar, então, sempre que vou, eu me depilo. E sempre ela reclama, ela fala: não precisa vir depilada. Só que eu tenho vergonha. E, ela fala: não precisa ter vergonha. Então, eu sempre me depilo e ela sempre reclama. (Silvia, entrevistada 08).

\footnotetext{
${ }^{3}$ As entrevistadas foram identificadas por nomes fictícios como forma de garantir o anonimato e o sigilo de suas informações.
} 
Essa fala evidencia um confronto entre o que é prescrito, pela enfermeira, e o que é redefinido pela entrevistada, segundo seus valores culturais. Se no início da fala é possível entender uma sugestão da enfermeira de que a paciente não precisa se depilar para o exame, o reforço dessa sugestão, em todas as vezes que a paciente vai para o exame depilada, mostra a existência de uma prescrição. Ao mesmo tempo, pelo lado da paciente, há uma reelaboração daquilo que é prescrito. Conforme relata, "ela sempre fala, mas eu me depilo. [...] E sempre ela reclama, ela fala: não precisa vir depilada. [...] Então, eu sempre me depilo e ela sempre reclama".

Silva (2008, p. 112), em estudo sobre as intervenções do operário em seu cotidiano de trabalho, destaca a existência de uma reelaboração criativa de normas prescritas do trabalho, pelo operário; de reinvenções e re-normalizações possíveis que singularizam os atos do trabalhador, de acordo com "seus próprios usos corporais, subjetivos, valorativos e simbólicos". A autora apoia-se em Ives Schwartz (2003) ao discorrer sobre a existência, no ambiente de trabalho, de normas prescritas e normas não prescritas, estas últimas, "criadas pelos indivíduos como forma de gerirem a si próprios, na defesa de seus valores e de sua subjetividade". A reinvenção permanente pelos indivíduos de ordens estabelecidas, em seu cotidiano, também tem suporte, para a autora, na teoria das práticas cotidianas de Certeau (1994).

De modo análogo, na presente pesquisa, percebe-se, na interação entre a entrevistada e a enfermeira, uma reelaboração e reinvenção pela primeira, daquilo que é prescrito, com vistas à defesa de valores próprios, bem como de sua subjetividade. Embora a enfermeira reforce a não necessidade de se depilar, reclamando, a cada encontro, quando vê que a paciente não seguiu suas orientações, a entrevistada permanece se depilando e diz, "sempre que vou, eu me depilo", (re)criando assim suas próprias normas (CERTEAU, 1994), na administração de sentidos próprios para suas práticas de cuidados do corpo.

O exame que realizam, o Papanicolau, é vivido pelas entrevistadas como uma obrigação, apesar do constrangimento que provoca, de modo que a retirada dos pelos revela, por um lado, a autonomia ${ }^{4}$ relativa da mulher nesse processo, que não segue a todas as recomendações da enfermeira e, por outro, a dimensão simbólica do corpo, como diz Silvia, entrevistada 08 , "A enfermeira do postinho fala que não precisa [fazer a depilação]. Ela sempre fala, mas eu tenho vergonha. Aí, eu me depilo".

Para a enfermeira, segundo a fala, não é preciso se depilar e também não é preciso ter vergonha, impressão não compartilhada pela entrevistada:

Eu tenho vergonha de estar ali cheia de pelo e a enfermeira olhar. Eu fico com vergonha, porque às vezes pode ser que dá alguma alteração e ela tem que chamar o médico. Eu fico constrangida. Esse exame é muito constrangido, mas a gente é obrigada a fazer. Então, eu tiro todo o pelo e assim me sinto mais à vontade.

"O caráter biocultural dos nossos atos corporais cotidianos", avalia Russo (2003: 188), evidenciase na maneira como homens e mulheres os executam. Em cada cultura, "Ser homem ou ser mulher, envolve um adestramento corporal, ao mesmo tempo físico e moral [...]" do qual faz parte um aprendizado sobre o que é ser "um homem de verdade" ou "uma mulher de bem", pondera a autora. Iniciado na infância, esse adestramento refere-se aos hábitos de higiene, banhos e cuidados corporais.

A presença de pelos nas pernas das mulheres pode ser considerado sujeira e a depilação acaba valendo como uma espécie de limpeza (RUSSO, 2003). Essa "limpeza" é considerada especialmente importante para a realização do exame Papanicolau, como revelaram as entrevistadas:

Só faço a depilação para fazer a coleta. É o jeito de a gente ser. Todas nós, mulheres, quando vamos fazer um Papanicolau, fazemos a depilação, porque acho que é chato

${ }^{4}$ Autonomia, no sentido Kantiano, da capacidade do indivíduo de dar a si mesmo as próprias regras. 
chegar lá toda amontoada, suja, cheia de cabelos para fazer um exame desses. Sempre, eu e minhas filhas, todas fazemos. É hábito, é higiene. Eu, independente, de fazer o exame faço isso, mas, principalmente, quando vou fazer o Papanicolau, eu me depilo. Toda vez. Eu fico constrangida se eu não depilar. Às vezes, eu deixo, porque eu tenho alergia. Mas, se eu vou passar no ginecologista ou vou fazer o exame, eu me depilo. Eu fico sem jeito de ir lá com cabelo. Eu fico constrangida. Qualquer um, na minha família diz: vou depilar para passar no ginecologista, relata Sandra, entrevistada 07.

Perguntada se ela só faria o exame se estivesse depilada, ela afirma:

Eu faço o exame, mas é coisa de jeito, cada um tem um jeito. No meu caso, eu acho que é falta de higiene. É que nem homem, tem homem que se depila, se cuida quando vai passar no médico, para o médico examinar. A mesma coisa é a mulher. Só que quando eu vou fazer o exame, eu me depilo. Eu acho falta de higiene, você fazer o exame sem se depilar. Toda vez que eu vou, eu faço. As minhas filhas também. Isso vem de família, aprendi com minha tia e com a minha mãe. Isso aí já vem de anos.

Em sua obra sobre os rituais de purificação, Mary Douglas (1991, p. 14), ressalta: "a impureza é, essencialmente, desordem. A impureza absoluta só existe aos olhos do observador [...] é ofensa contra a ordem. Eliminando-a, não fazemos um gesto negativo; pelo contrário, esforçamo-nos positivamente por organizar o nosso meio". A impureza revela, assim, que algo está fora de seu lugar; ela introduz uma desordem em nosso mundo.

A separação entre o que é limpo e sujo reflete o modo como os sistemas de classificação social tornam nossa experiência social inteligível. A impureza mistura o que não deve ser misturado, ao mesmo tempo em que não leva em conta as fronteiras sociais e simbólicas que mantém o mundo social em ordem.

Nessa perspectiva, tanto os rituais de purificação, presente em sociedades tradicionais, quanto as regras de higiene, próprias das sociedades modernas, correspondem ao esforço para dar um sentido à nossa experiência vivida: "Os rituais de pureza e de impureza dão certa unidade a nossa experiência. [...] Por meio deles, as estruturas simbólicas são elaboradas e exibidas à luz do dia. No quadro destas estruturas, os elementos díspares são relacionados e as experiências díspares adquirem sentido" (DOUGLAS, 1991, p. 15).

A oposição limpo e impuro assume, assim, um valor moral capaz de qualificar a experiência vivida. Por isso, é comum nos referirmos à "sujeira" como algo mal, impuro, como um dano que alguém nos fez no passado. Limpar significa purificar, restabelecer a ordem de sentido, afastando-nos do mal.

É justamente esse significado moral que é corporificado na experiência das mulheres entrevistadas quando narram as práticas de "limpeza" do corpo, ao se depilarem para fazerem o exame de Papanicolau.

Silvia e Sandra fazem a depilação como forma de se prepararem para a coleta de material para o exame. Silvia explica que a prática de se depilar tem a ver com o fato de se sentir envergonhada e constrangida em expor seu corpo, em estar cheia de pelos, diante dos profissionais de saúde - enfermeira e médico. Sandra, por sua vez, aponta a vergonha e o constrangimento em se mostrar, como diz, "toda amontoada e cheia de cabelos ao ir ginecologista e fazer o exame de Papanicolau".

Em suas práticas de depilação, ambas as entrevistadas acionam um sistema moral que concebe os pelos como algo impuro; algo que não pode estar presente durante a coleta de material para o exame. Seguindo a linha aberta por Douglas, os pelos pubianos são considerados "matéria fora do lugar", particularmente, durante a realização do exame de Papanicolau, pois são considerados "sujeira".

A entrevistada Sandra, faz referência a esse aspecto, argumentando que a raspagem dos pelos pubianos é uma questão de higiene, pois ela se sente "suja" quando não se depila. Ela também nos diz que aprendeu isso com sua tia e sua mãe, um aprendizado que já vem de anos, evidenciando o fato de a cultura familiar fornecer a ela a ordem de sentido na qual vai se estabelecer o sistema de crenças e de 
classificação social em relação aos cuidados do corpo.

Do mesmo modo que os pelos pubianos, para as mulheres entrevistadas, o sangue menstrual é considerado impuro, devendo, por isso, ser evitada a realização do exame nesse período.

A esse respeito, Leal (2001) observa que o corpo feminino é concebido, nos grupos populares, a partir dos movimentos de abertura e fechamento, que indicam seu bom funcionamento. Para a autora (2001, p. 28), a menstruação e a concepção são fenômenos que se encontram interligados e representados como o momento em que o corpo feminino está aberto: "No jogo de significações dos humores do corpo, que envolvem a menstruação e a concepção, a representação do corpo feminino como algo que se abre e fecha é determinante sobre todas as outras e chave para compreendermos a lógica da reprodução [...]. O sangue menstrual é específico e indicador da condição de fertilidade feminina.

As representações do sangue indicam, portanto, que ele pode ser concebido ora como um sinal de fertilidade da mulher, ora como algo sujo, um resto que deve ser evacuado (DOUGLAS, 1991; HELMAN, 2003). Ainda segundo Leal (2001, p. 28):

o sangue menstrual é, alguns momentos, indicado como algo sujo, algo a ser eliminado, em outros momentos como um fluído que opera a limpeza do corpo, às vezes como um filtro, às vezes como um resto.

O sangue, visto como resto, também é referido por Marcela, entrevistada 09, que atrela sujeira à conjugação entre pelo "grande" e menstruação. Quando indagada sobre a preparação do exame, comenta:

A enfermeira manda não ir fazer o exame nos dias da menstruação. Ela fala para deixar passar sete dias, porque pode sangrar muito. Ela fala também para não ter relação sexual três dias antes. Eu obedeço à ordem. Eu também tiro os pelos com barbeador. Porque, eu acho que é feio e eu fico mais limpinha. Assim, eu acho que é mais fácil para eles fazer o exame. Eu não gosto de ficar com pelo grande. Eu acho mais limpo. Até quando está descendo, quando molha, fica parecendo que está sujo.

Da mesma maneira que a entrevistada Silvia, Marcela aponta que o exame não deve ser feito durante a menstruação. A recomendação feita pela enfermeira é entendida como uma "ordem", o que denota a autoridade que o profissional de saúde tem diante dela, que obedece. Como discute Breton (2011, p. 128), "o saber biomédico é, de certa maneira, a representação oficial do corpo humano hoje [...]”, sua autoridade é reconhecida, a ponto de uma recomendação do profissional de saúde poder ser apreendida como ordem. Como diz a entrevistada, "Ela fala também para não ter relação sexual por três dias antes. Eu obedeço à ordem".

Marcela também se depila para realizar o exame, pois considera "feio" e que fica "mais limpinha". Ela também relaciona a depilação à sujeira, conjugada com a menstruação, pois, "quando está descendo, quando molha, fica parecendo que está sujo," diz.

O movimento de descida do sangue menstrual corresponde a essa ideia de que o corpo da mulher está aberto. $\mathrm{O}$ aspecto molhado, úmido do sangue, reforça a representação de algo sujo, que deve ser evitado durante o exame, assim como a presença dos pelos.

Ao cortarem os pelos pubianos, as mulheres creem que facilitam a realização do exame, de maneira que ele se torna mais aceitável, tanto para ela, que se sente melhor, mais limpa, quanto para o médico que a examina. Nessa compreensão, a mulher passa a fazer parte do exame não apenas como objeto de uma intervenção médica, mas também como um sujeito responsável por sua execução. Não por acaso, mesmo diante das reclamações da enfermeira, Silvia depila-se para fazer o exame. Na lógica das mulheres entrevistadas, a raspagem dos pelos tem um sentido físico, pois facilita a realização do exame e, 
ao mesmo tempo, um sentido moral, pois, como dizem, com a depilação, ficam mais à vontade e menos constrangidas diante do e da profissional de saúde.

"Só faço a depilação para fazer a coleta. Todas nós, mulheres, quando vamos fazer um Papanicolau, fazemos a depilação, porque acho que é chato chegar lá toda amontoada, suja, cheia de cabelos para fazer um exame desses [...]" revelou Sandra, entrevistada 07. A depilação é feita, então, como um ritual de limpeza, de purificação.

Mauss (2002, p. 36) destaca que os atos, mesmo quando individualizados, também podem ser entendidos como rituais, na condição de que "haja neles alguma coisa de regulamentado, regrado". Como esclarece o autor, o que distingue os atos cotidianos, as festas e os jogos dos ritos é que os primeiros não são eficazes por si mesmos, dependendo das circunstâncias em que são praticados; eles não possuem uma "verdadeira eficácia material". Já os ritos são eficazes por si mesmos e são capazes de "exercer uma ação sobre certas coisas", de maneira que "um rito é uma ação tradicional eficaz".

Nesse sentido, o rito não se caracteriza apenas pelos seus aspectos formais, mas, sobretudo, por sua capacidade de suscitar a crença em seus efeitos, assumindo, assim, um caráter simbólico; sua eficácia está ligada diretamente a certas práticas simbólicas capazes de reafirmar a crença daqueles que os vivenciam.

É nessa linha de compreensão que a depilação para a realização do exame Papanicolau pode ser compreendida como um ritual de purificação para as mulheres que realizam.

Junto com outras práticas - não estar menstruada e a abstinência sexual de três dias antes do exame - a depilação compõe o conjunto de "regras de evitação" que acionam um sistema moral que orienta a experiência do exame de Papanicolau. As regras de evitação foram estudadas por Douglas (1991) e relacionadas às prescrições e proscrições que visam proteger os indivíduos da doença ou do mal nas sociedades tradicionais. Esse conjunto de regras descreve e organiza o mundo social, tornando possível estabelecer uma ordem em oposição ao caos contra o qual se confronta a experiência vivida.

No exame Papanicolau, as regras de evitação asseguram certo ordenamento e controle da mulher sobre seu corpo. Essas interdições relativas à impureza e à pureza do corpo feminino visam garantir às mulheres organizar sua experiência diante da obrigação de fazer um exame, considerado constrangedor.

\section{VERGONHA, CONSTRANGIMENTO E DOR NA EXPERIÊNCIA DO EXAME CLÍNICO}

Comumente, nas camadas populares, diferente do que ocorre nas camadas superiores, os indivíduos vão com menor frequência ao médico. Adam e Herzlich (2001, p. 75) apud Boltanki (1971), destacam o fato de que nos meios mais favorecidos há maior interiorização das categorias do saber médico, tendo em vista alguns fatores, dentre os quais, a aproximação cultural, de procedência social e de visão de mundo dos universos sociais, o que facilita a comunicação e compreensão das informações transmitidas pelo médico. Como elabora a autora, esses indivíduos "estão mais inclinados a decodificar sua doença e a conversar sobre a mesma conforme as categorias da Medicina". Há assim, uma aproximação com o discurso científico e suas práticas.

Ao mesmo tempo, nas sociedades contemporâneas ocidentais, domina o saber médico, responsável por transmitir "a todos os conceitos e as explicações sobre a natureza e as causas de seu problema" (ADAM; HERZLICH, 2001). Esse saber, hegemônico, define-se por ser fundamentalmente "biológico" (LAPLANTINE, 2002). Uma vez dominante, ele informa a todos sobre as doenças e suas causas. É assim que termos médicos são (re)apropriados, também nas classes populares, como verificado na presente pesquisa. 
Todavia, embora dominante, o modelo ontológico é ele mesmo uma interpretação (LAPLANTINE, 2001). O doente tem, a seu lado, modelos explicativos para os males que o afetam, construindo para sua compreensão, modelos explicativos individuais, alicerçados em raízes culturais e de sua classe social. Como desenvolvem Adam e Herzlich (2001), os modelos explicativos da doença e suas causas vão estar apoiados em conceitos e estruturas de referências interiorizadas e ressignificadas conforme os grupos sociais e culturais a que pertençam, bem como a experiências vividas pelos indivíduos.

Apoiadas em referências comuns dos grupos sociais de pertencimento, as mulheres entrevistadas compartilham não apenas sentimentos similares em relação à experiência do exame Papanicolau, como também as mesmas interpretações sobre a causa da dor que podem vir a sentir. Dor, constrangimento e vergonha são os sentimentos que expressam essa experiência com o exame.

Uma das entrevistadas relata o modo como a intervenção pelo exame ocorre:

Ela [a profissional de saúde] colhe o que tem que colher e pronto. O procedimento do Papanicolau e pronto. Ela fala que tem que relaxar; ficar sossegada e não precisa se preocupar. Ela põe o bico lá e faz a curetagem normal (Sandra, entrevistada 07).

O Instituto Nacional de Câncer-INCA- indica o modo como o exame de Papanicolau deve ser realizado:

Para a coleta do material, é introduzido um instrumento chamado espéculo na vagina (conhecido popularmente como "bico de pato", devido ao seu formato). O profissional faz a inspeção visual do interior da vagina e do colo do útero. A seguir, o profissional promove a escamação da superfície externa e interna do colo do útero com uma espátula de madeira e uma escovinha. As células colhidas são colocadas numa lâmina para análise em laboratório especializado em citopatologia (Brasil, 2015b).

$\mathrm{Na}$ presente pesquisa, as mulheres entrevistadas revelam como o sentimento de vergonha e constrangimento acompanha essa experiência com o exame: "Só acho um pouco chato de fazer. [o Papanicolau]. É constrangedor" (Maísa, entrevistada 04). Marcela, entrevistada 09, ressalta a vergonha na realização do exame:

Agora, para fazer o exame [de Papanicolau], eu tenho vergonha. Ah! Eu tenho vergonha de abrir as pernas, sei lá. Tenho vergonha, não sei o porquê. Eu não sei se é porque eu sou ignorante, mas que eu tenho vergonha, eu tenho (Marcela, entrevistada nove).

Outra entrevistada, Yolanda, que apesar de reforçar a importância da realização periódica do exame, também revela o receio e o desconforto por ter que tirar a roupa e ficar deitada, com as pernas afastadas, para a coleta do material, no exame:

Faço o exame com receio, porque não é fácil. Você tem que deitar ali, tem que tirar a roupa. Só que depois você relaxa, porque é uma coisa que é natural. Precisa fazer o Papanicolau.

Estudo realizado por Aguilar e Souza (2015, p. 368), sobre a realização do exame Papanicolau, também destacaram esse aspecto. Como mostram as autoras, a vergonha de realizar o exame foi o sentimento mais presente entre as mulheres. Conforme apontam, "a exposição do corpo no momento do 
procedimento remete a questões referentes à sexualidade, podendo aflorar sentimentos negativos de bloqueio e conflito para algumas mulheres. E estas resistências são geralmente externadas como vergonha e constrangimento".

Esse sentimento de vergonha está fortemente relacionado com as relações de gênero, sobretudo, quando a mulher tem que expor seu corpo diante de um profissional do sexo masculino. É o que deixa entrever Marcela, entrevistada 09, quando indagada se prefere fazer o exame com um profissional homem ou mulher: "Ah, eu prefiro mulher. Deus me livre de fazer com os homens, não".

Ou ainda, nas palavras de Silvia, entrevistada 08, quando relata que sua mãe, que morreu do câncer do colo do útero, nunca tinha feito o Papanicolau, por não aceitar expor sua intimidade diante de um homem, que não fosse seu marido:

Ela nunca fez exame de partes íntimas. Ela nunca fez. Porque para ela, que morava na roça, não era normal outro homem ver as partes intimas dela, que não fosse o marido dela. A mesma coisa aconteceu com minha avó, ela tem 70 anos e também nunca fez esse exame.

As relações de gênero, social e historicamente construídas, definem as práticas em relação ao corpo e à sexualidade, de forma que a exposição da genitália feminina e a manipulação das zonas erógenas da mulher pelo profissional de saúde podem gerar vergonha e constrangimento às mulheres, por se tratar de ações consideradas moralmente incorretas, levando-as muitas vezes, por este motivo, a não realizarem o exame de Papanicolau, principalmente, quando o profissional é do sexo masculino, como ressaltam as entrevistadas.

O encontro das mulheres com os profissionais de saúde estabelece relações e percepções diferenciadas, segundo os gêneros, tanto das pacientes, quanto dos profissionais. Como discute Rohden (2006, p. 158), não apenas o gênero, como o sexo e a sexualidade "são fatores que explicita ou implicitamente fazem parte do processo de elaboração do saber médico e da atuação cotidiana dos profissionais desse campo.”. Assim, segundo a autora, há todo um conjunto de procedimentos realizados com vistas a evitar qualquer contato que possa ser interpretado como sexualizado, especialmente nas situações onde há maior proximidade física entre o paciente e o médico, como no exame de Papanicolau.

Para as mulheres entrevistadas, o desconforto ou mesmo a interdição com relação ao gênero, definem o encontro com o profissional de saúde, na manipulação das partes do corpo consideradas íntimas. Como destaca a entrevistada Silvia, a sua mãe nunca fez exame de partes íntimas porque para ela, que morava na roça, "não era normal outro homem ver as partes intimas dela", que não fosse o marido dela, revela.

O sentimento de vergonha e o constrangimento, assim como tudo o que diz respeito ao humano, não são dados "naturais", mas construídos histórica e socialmente (LE BRETON, 2006; 2009). Sentir ou não vergonha tem a ver com a internalização daquilo que é socialmente exigido de cada um, em determinado tempo e lugar. Assim, a maneira como cada indivíduo se comporta e sente vai estar relacionado ao que é considerado aceitável ou proibido, em dado tempo e lugar (ELIAS, 1994). Esse comportamento que é informado, em cada sociedade e em cada época, por regras que definem o que é considerado adequado para o homem e para a mulher, faz referência a diferentes usos do corpo; a diferentes técnicas corporais.

Mauss ([1936] 2003, p. 401), ao discorrer sobre as técnicas do corpo, descreve-as como "maneiras pelas quais os homens, de sociedade a sociedade, de uma forma tradicional, sabem servir-se de seus corpos". Logo, os usos do corpo, dele fazendo parte os cuidados do mesmo, são definidos pelo universo social que o produz e transmitidos de geração a geração. 
Em nossa sociedade, cuidar do corpo e da saúde significa estabelecer o encontro com a medicina (ADAM; KERZLICH, 2001). Hegemônico em nossa sociedade, o modelo anatomofisiológico é responsável pelas explicações oficiais sobre o corpo, suas transformações, os males que os afetam (LAPLANTINE, 2001) e os cuidados com a prevenção das doenças, cujas orientações caminham na direção da busca de uma vida equilibrada, regrada, tranquila; uma vida saudável cada vez mais associada a uma vida "moralmente aceitável" (RUSSO, 2006).

Preventivo, o exame Papanicolau é vivenciado pelas mulheres entrevistadas como uma experiência na qual se expõe a intimidade diante do profissional de saúde. Ao expor o corpo para a coleta de material biológico, elas revelam como o exame de Papanicolau torna visível a experiência corpórea, evidenciando o corpo como uma construção simbólica.

Durante a realização do exame, as mulheres entrevistadas se encontram com o serviço de saúde e mantém uma relação direta com o modelo da biomedicina, passando a viver o processo de medicalização de seus corpos (LE BRETON, 2011).

A literatura socioantropológica tem enfatizado o modo como, sobretudo, a partir do século XIX, o corpo da mulher é objeto das intervenções do saber médico.

Exemplo disso é a obra de Vieira $(1999 ; 2002)$ sobre a medicalização do corpo feminino, na qual sublinha a maneira como o corpo da mulher se transforma em objeto de saber e prática médica, a partir da condição social de gênero, de maneira que "a medicalização desse corpo particulariza-se nas implicações específicas da reprodução humana, relacionada à sua condição orgânica" (1999: 67).

Nesse processo, a medicina produz um conhecimento sobre o corpo da mulher, baseado em sua "natureza biológica". Nas palavras de Vieira (1999, p. 68):

O processo histórico de medicalização do corpo feminino passa, necessariamente, pela ideia de que existe uma natureza biológica determinante e dominante da condição feminina. É justamente por meio dessa concepção que a medicina poderá se apropriar do corpo das mulheres.

Rohden (2001, p. 198) também discute esse aspecto, mostrando que:

Nas tentativas de definição da diferença sexual com base na biologia e de delimitação dos papéis sociais atribuídos a cada sexo, quase sempre colocava em questão a distinção entre o que é natural e o que é social ou cultural. Eram frequentes as aproximações entre a mulher e a natureza e o homem e a cultura.

Buscando o controle dessa "natureza instável", a medicina vai se ocupar da saúde da mulher, particularmente, do processo reprodutivo, por meio da obstetrícia moderna e da ginecologia (ROHDEN, 2001) ${ }^{5}$. O saber médico opera, assim, como um "dispositivo de poder" Foucault (1997), na medida em que possibilita esquadrinhar, nomear e classificar o corpo da mulher, tomando-o como objeto de controle do conhecimento e da prática médicos.

Como enfatiza Rohden (2006, p. 176):

As especialidades médicas dedicadas à mulher, em especial, a ginecologia, se constituem a partir da noção de que o corpo e o papel social femininos são determinados pela função pro criativa. Em contraste com o homem, a mulher aparece como marcada pelos traços

\footnotetext{
${ }^{5}$ Como discute Rohden (200, p. 203), a "ginecologia, além de tratar dos fenômenos relativos aos órgãos reprodutivos na mulher, constitui também uma verdadeira ciência da feminilidade e da diferenciação entre homens e mulheres".
} 
biológicos que definem a maternidade e que são também a fonte de todas as suas virtudes, os seus pecados e as suas doenças.

O exame Papanicolau permite a observação e antecipação de "anormalidades" do aparelho reprodutivo feminino, bem como o controle sobre a saúde reprodutiva da mulher.

Por meio das especialidades médicas dedicadas à mulher e sua saúde reprodutiva, o médico adquire um papel social mais amplo, como educador, e o corpo feminino passa a ser controlado e normatizado, principalmente, pelo saber médico.

Esse saber evidencia-se também pelos termos médicos que são reproduzidos e reapropriados pelos indivíduos ao falarem de seu estado de saúde, nas diferentes camadas sociais. Como desenvolve Boltanski (2004), os membros das camadas populares se apropriam dos termos médicos, que passam a fazer parte de seu repertório para se referir aos episódios de doença, à sua saúde e ao seu corpo.

É nessa linha que podemos compreender o modo como as mulheres entrevistadas se referem ao seu corpo e à necessidade de realizarem o exame de Papanicolau:

Eu faço [o Papanicolau], porque as mulheres aparecem falando lá no Keralux que tem mioma, câncer, a gente escuta falar. Minha mãe mesmo também tinha mioma, mas tiraram por baixo e ela não precisou nem operar. Mas eu nunca tive mioma (Marcela, entrevistada 09).

Indagada se tinha retirado todo o mioma, a entrevistada 06, Márcia, responde:

Tirei o útero e as trompas, ficaram somente os ovários. Fiquei um ano tratando do mioma e depois de três hemorragias, eu tive tirar o útero. Só fiquei com o colo do útero. Daí, eu faço o Papanicolau a cada seis meses. Depois da cirurgia, o médico achou conveniente fazer o exame depois de um ano. Daqui a um mês, mais ou menos, eu vou marcar para fazer o Papanicolau.

Como visto nas entrevistas, os contornos do processo saúde-doença e do corpo são delineados pela apropriação do conhecimento médico, dos termos que este usa, e que passam a compor o campo semântico das mulheres entrevistadas. Exemplo disso, também está presente na narrativa de Yolanda, entrevistada 01, ao falar sobre a necessidade de a mulher fazer o exame de Papanicolau e a mamografia:

Não é só conversa, realmente ajuda. A mulher tem que fazer mesmo. Ela tem que se conscientizar, porque previne. Se a doença for detectada a tempo, tem mais chances de cura. Isso não é conversa, é a realidade mesmo. Eu acho que a mulher tem que fazer sim, uma vez por ano [...]. Ela tem que fazer todo o check up. Se ela não tem quarenta anos, ela tem que fazer o ultrassom das mamas. Se ela já tem 40 anos, ela já faz a mamografia. Mas antes dos 40, a mulher tem sim que fazer tudo isso.

Nessa narrativa, os resultados do exame de Papanicolau ganham estatuto de verdade, uma vez que ele pode revelar a doença e preveni-la. Como desenvolve Le Breton (2011, p. 309), as "imagens tornam-se hoje as peças para a convicção de uma realidade sempre mais evanescente. O mundo faz-se amostragem (e, portanto, demonstração; ele organiza-se antes de tudo, nas imagens que lhe dão a ver).”. Na medicina, a imagem do corpo médico revela a concretude do mal. A visibilidade, analisa o autor, "é o feito do escalpelo, que rasga tecidos inertes e os compara, assim como as afecções e as malformações, para colocar em evidência o vestígio sensível do mal, a concretude carnal da doença (LE BRETON, 2011, p.315), justificada também, no exame Papanicolau, pela ideia de controle, prevenção e 
antecipação da doença.

Como diz a entrevistada, "Isso não é conversa", "é a realidade mesmo". O exame, que faz ver o interno do corpo, revelado por imagens médicas, produz essa realidade, que busca a prevenção das patologias. Reafirma-se aí a crença no saber médico, nas suas possibilidades de diagnóstico, tratamento e cura das doenças.

As entrevistadas também revelam o modo como compreendem e avaliam a realização do exame de Papanicolau, destacando seus incômodos: "Eu acho ruim fazer [o Papanicolau]; eu acho ruim fazer o papa porque dói, eu acho ruim fazer o papa porque dói, dói bastante.” (Vânia, entrevistada 02). Mari, entrevistada 03 , também traz essa ideia:

Ah, não é bom; é horrível fazer aquele exame, mas tem que fazer. Não machuca, não. Tem uns [profissionais de saúde] que machucam, outros não, depende das mãos, tem uns com mão pesada, outros com mão leve. (Mari, entrevistada 03).

Marcela, entrevistada 09, também faz a mesma avaliação sobre o modo como foi assistida durante a realização do exame:

Ela colocou aquele aparelho uma vez e não conseguiu. Ela colocou de novo e mandou relaxar. Doeu e saiu ardendo. No outro dia, minha barriga endureceu e ficou doendo [...] Ela tinha a mão muito pesada.

Nesses casos relatados, a dor tem um sentido solitário, marcada pela não comunicação com o profissional de saúde, uma vez que não há uma negociação de seus significados com o médico que faz o exame, sendo a dor isolada; dor da paciente. Na experiência do exame, enquanto o médico pede para a paciente relaxar, ela, ao seu lado, comenta, na entrevista, que doeu e saiu ardendo.

Para ambas as entrevistadas que falam do incômodo do exame, a dor encontra inteligibilidade na "mão pesada" do médico. Como diz Mari, entrevistada 03, "Tem uns [profissionais de saúde] que machucam, outros não, depende das mãos, tem uns com mão pesada, outros com mão leve". Marcela reforça a ideia, "Doeu e saiu ardendo [...] Ela tinha a mão muito pesada". Mas a dor é suportada, pois, como diz Marcela, "é horrível fazer aquele exame, mas tem que fazer".

Nessa, como em outras falas, a dor é suportada, mesmo com o desconforto no momento da realização do exame. Atrelada à confiança e à consideração da importância da realização do exame, parece haver, no caso das mulheres pesquisadas, uma maior tolerância à dor, que pode ser, em parte, compreendida pelo lugar social que ocupam. As mulheres entrevistadas são membros de camadas populares, a maioria praticante de alguma religião, o que pode conduzir a uma maior tolerância à dor e à submissão ao saber médico, que prescreve a necessidade da realização do exame preventivo de câncer do colo do útero.

Como argumenta Sarti (2001, p. 10), a "dor como realidade social é simbolizada, ainda, mediante os distintos lugares sociais dos indivíduos. Dentro de uma mesma sociedade, os indivíduos são portadores de condições sociais diferenciadas, de acordo com as clivagens sociais, entre elas, as de gênero, de classe e etnia, qualificando a realidade da dor. Pode haver maior ou menor tolerância à dor, conforme aquilo que do indivíduo se espera, segundo seu lugar social".

Atrelada ao lugar social que ocupam, a dor é suportada porque é inteligível, faz sentido para as mulheres e o sentido da dor revela-se na "mão pesada do médico". As mulheres entrevistadas fazem uma avaliação dos profissionais de saúde e do modo como o exame foi realizado, demarcando a oposição entre os marcadores "leve" e "pesado", para se referir ao modo como o profissional realiza o exame 
de Papanicolau.

A "mão leve" significa que o médico conseguiu fazer com que a paciente não sofresse dor, não fosse machuca no exame. O profissional com "mão leve" é qualificado como atencioso, sensível e acolhedor, em oposição à "mão pesada", que faz dele desatencioso e mesmo insensível à dor e ao sofrimento.

Em ambos os casos, há a crença na eficácia do exame, bem como nos saberes dos médicos que o realizam. A dor é assim compreendida pela paciente, ganhando sentido nesse registro paradoxal da crença na eficácia técnica do médico que, embora dotado de conhecimento para a realização do exame, pode apresentar "mãos pesadas", que machucam e causam dor, esta, já esperada, embora não desejada, compreendida. E é nessa confiança que está a dimensão simbólica (LÉVI-STRAUSS, 1970) da relação médico paciente, marcada pela autoridade médica, que a compreensão da dor da mulher se assenta.

\section{COMENTÁRIOS FINAIS}

Em meio ao processo de medicalização e prescrições biomédicas, as mulheres entrevistadas acionam um mecanismo de ordenamento do corpo no exame Papanicolau, isolando aspectos considerados impuros do seu corpo. Por essa via, buscam manter um controle relativo do exame ao criarem suas próprias normas de apresentação de seus corpos. Na busca desse controle, gerenciam a si mesmas, conservando e expressando seus valores em relação ao corpo feminino, o que evidencia a dimensão simbólica do corpo e o caráter social das emoções, em especial, da dor, do constrangimento e da vergonha que acompanham a circunstância de realização do exame.

Durante esse exame clínico, a confiança das mulheres no saber e na técnica biomédica, bem como a avaliação sobre o modo como os profissionais de saúde operam o saber e manejam o corpo no exame, tornam inteligíveis a dor que ali sentem, enquanto a preparação do corpo para o exame, nem sempre coincidente com as prescrições biomédicas, bem como os sentimentos que acompanham essas situações, antes e durante o exame, explicitam a dimensão simbólica do corpo e sua inscrição como corpo feminino de uma determinada camada social.

\section{REFERÊNCIAS}

ADAM, P ; HERZLICH, C. Sociologia da doença e da medicina. Bauru: EDUSC, 2001.

AGUILAR, R.P; SOARES, D.A. Barreiras à realização do exame Papanicolau: perspectivas de usuárias e profissionais da Estratégia de Saúde da Família da cidade de Vitória da Conquista-BA. Revista Physis, v. 25, n.2. p. 359-379, 2015.

BOLTANSKI, L. As classes sociais e o corpo. São Paulo: Paz e Terra, 2004.

BRASIL. Ministério da Saúde. Secretaria de Atenção à Saúde. Departamento de Atenção Básica.

Controle dos cânceres do colo do útero e da mama. 2. ed. Brasília: Editora do Ministério da Saúde, 2013.

CAMPOS, E. A. Olhando de perto: o método etnográfico na pesquisa em saúde. In. Melo, L., Gualda, D.M.R. e Campos, E.A. (org). Enfermagem, antropologia e saúde. São Paulo: Manole, 2013.

CERTEAU, M de . A invenção do cotidiano: artes de fazer. Rio de Janeiro: Vozes, 1994 
DOUGLAS, M. Pureza e perigo: ensaio sobre a noção de poluição e tabu. Lisboa: Edições 70, 1991.

ELIAS, N. O processo civilizador. Uma história dos costumes. Rio de Janeiro: Zahar, 1994.

FONSECA, C. Família, fofoca e honra: etnografia de relações de gênero e violencia em grupos populares. Porto Alegre: Ed. UFRGS, 2004.

FOUCAULT, M. Resumo dos Cursos do Collége de France (1970-1982). Rio de Janeiro: Zahar, 1997.GEERTZ, C. A interpretação das culturas. Rio de Janeiro: Guanabara, 1989.

HELMAN, C. Cultura, Saúde e Doença. Porto Alegre: Art Med, 2003.

KANT, I. (1987). Crítica da razão pura. São Paulo: Nova cultural, 1987.

LAPLANTINE, F. Antropologia da doença. São Paulo: Martins Fontes, 2002.

LE BRETON, D. Antropologia do corpo e modernidade. Petropolis-RJ: Vozes, 2011

LE BRETON, D. As paixões ordinárias: antropologia das emoções. Petrópolis: Vozes, 2009.

LE BRETON, D. Sociologia do corpo. Petrópolis/RJ: Vozes, 2006.

LEAL, O.F. Sangue, fertilidade e práticas contraceptivas. In Leal, O.F (org). Corpo e significado: ensaios de antropologia social. Porto Alegre: Ed. UFRGS, 2001

LÉVI-STRAUSS, C. A eficácia Simbólica. In Antropologia Estrutural. Rio de Janeiro: Tempo Brasileiro, 1970.

MAUSS, M. As técnicas do corpo. In Mauss, M (org), Sociologia e Antropologia. São Paulo: Cosac \&Naify. ([1936] 2003).

MAUSS, M. La prière en Treamblay, J.M (Comp). Classiques des sciences sociales. Université du Quebec, 2002.

MINAYO, M.C.S. O Desafio do Conhecimento: Pesquisa Qualitativa em Saúde. São Paulo: HUCITEC, 2009.

ROHDEN, F. Sexualidade e gênero na medicina. In Souza, A.N. e Pitanguy, J. (comp.). Saúde, corpo e sociedade. Rio de Janeiro: Ed UFRJ, 2006.

ROHDEN, F. Uma ciência da diferença: sexo e gênero na medicina da mulher. Rio de Janeiro: Editora FIOCRUZ, 2001.

RUSSO, J. (2006). Biomedicina e racionalidade científica no ensino contemporâneo da área da saúde.In Souza, A.N ; Pintanguy, J (org). Saúde, corpo e sociedade. Rio de Janeiro :UFRJ, 2006.

SARTI, C.A. A dor, o indivíduo e a cultura. Revista Saúde e Sociedade. n. 1, p. 3-13, 2001.

SILVA, C.F. A gestão de si na reinvenção das normas: práticas e subjetividades no trabalho. Revista Saúde e Sociedade, v.17, n.4, p. 111-123, 2008.

SHWARTZ,Y. Travail et ergologie: entretiens sur l'activité humaine. Toulouse: Octarès, 2003.

VIEIRA E.M. A medicalização do corpo feminino. In Giffin, K.; Costa, A S.H. Questões da saúde reprodutiva. Rio de Janeiro: Ed. Fiocruz, 1999.

VIEIRA E.M. A medicalização do corpo feminino. Rio de janeiro: Ed. Fiocruz, 2002. 